\title{
OHSAS 18001: 2007 IN THE PRACTICE OF BULGARIAN ORGANIZATIONS Radka Ivanova ${ }^{1}$
}

\begin{abstract}
Using appropriate methods and management tools is a prerequisite for the effective functioning of any organization. Staff are particularly sensitive to the conditions under which they have to work, so employers should ensure compliance with specific rules and procedures, depending on the characteristics of the particular field of activity. In this regard, the implementation and certification of OHSAS 18001 is of great importance as the possession of a certificate can be considered as a guarantee of compliance with the relevant requirements. Therefore, in this paper we aim to present the main features of OHSAS 18001: 2007 currently in force as well as the peculiarities of the standard for a safe and healthy working environment which has been preparing since 2013 by the International Organization for Standardization under the name ISO 45001 Occupational health and safety management systems - Requirements with guidance for use. Currently, ISO 45001 is waiting for its completion and final publication, after which the process of transition from OHSAS 18001: 2007 to ISO 45001 will start, providing three years as a grace period for implementing the new requirements throughout organizations. We are also interested in the extent of the OHSAS 18001 standard dissemination among Bulgarian organizations, which is monitored in the sectorial and regional directions.
\end{abstract}

JEL Classification Numbers: L15, M12, M54; DOI: http://dx.doi.org/10.12955/cbup.v6.1157

Keywords: management, standard, standardization, certification, safety, work place

\section{Introduction}

Creating favourable working conditions is among the key factors for building prerequisites for an effective workflow in organizations. In accordance with existing legislative measures, each employer must ensure that the environment, in which the activity is carried out, is not risky for the staff. In this context, in international aspects, specific requirements are formulated in a standard, the certification of which is evidence of the management's responsibility to ensure a healthy and safe working environment.

\section{OHSAS 18001:2007 Specification}

The British standard OHSAS 18001 is defined as the most widely recognized management system for healthy and safe working conditions. It is currently being implemented in its version from 2007, when its latest revision was published. OHSAS 18001: 2007 has been gradually gaining international recognition and application, along with ISO standards. As a result, a number of organizations are certified under the basic ISO 9001 standard and at the same time according to OHSAS 18001 to form an integrated quality management system. The OHSAS 18001 standard is defined as a structured management system that defines the basic structure and powers to stimulate and regulate conditions to ensure safety and well-being at work and to protect human health. Compliance with the provisions arising from OHSAS is regarded as a prerequisite of the reduction of labour incidents and accidents during the work process.

The success of OHSAS 18001 standard depends on a number of factors, and as the key ones among them T. Ling, F. Hashim, C. Liang (2015) have defined the following: the leadership commitment, employees/workers involvement, promotion and recognition, as well as an appropriate environment. The commitment of the leadership is expressed in the manifestation of desire and concrete actions to distinguish the difference between right and wrong in order to correct the inaccuracies. Senior management should provide the necessary financial resources and sufficient resources required for each stage of development and implementation. Constant support to the efforts of all staff to maintain a safe work environment in organizations is a way to demonstrate leaders' commitment to create a healthy working environment.

Participation of employees/workers in relation to OHSAS 18001 system is expressed in the need to integrate them in the course of construction and namely in the management of the system. The perception of the outlined staff safety rules shows their commitment to the creation and maintenance of a safe working environment. Commitment can be achieved through the participation of workers as safety representatives, including supervisory functions in specially established committees / teams for this.

\footnotetext{
${ }^{1}$ University of Economics - Varna, Bulgaria, Department of Management and Administration, r.ivanova @uevarna.bg
} 
Promotion and recognition as important factors for the successful implementation of OHSAS are associated with the need to develop policies, strategies, procedures to achieve internal coherence and harmonization in the organization. Applying an appropriate remuneration system, including nonmaterial incentives, is a prerequisite for more effort in the desired direction. Creating the appropriate conditions for the transmission of information between the employed in an organization is also important as it gives the opportunity to implement up-to-date information concerning requirements and changes in OHSAS 18001.

An appropriate environment, also called a supportive environment, and means to create a harmonious relationship between people in the organization and unity in thinking about the need for healthy and safe working conditions and the benefits for every person and working teams as a whole. Successful implementation of OHSAS 18001 also involves the withdrawal of group norms in the field of work safety and their imposition as the normal behaviour of employees in the organization. Researchers define that it is extremely important that requirements of OHSAS 18001 standards become part of the organizational culture concerning attitude to work and its safety for human health.

\section{Features of the new ISO 45001 standard}

The establishment of healthy and safe working conditions is important for certain areas of activity characterized by a higher degree of risk of occurrence of factors that can harm people. Because of this, BS OHSAS 18001, which emerged as a national standard, acquires international importance. The existing general guidelines for creating a healthy working environment, the different national standards however, do not have uniform consistency. In this regard, and with the aim of unification, the International Organization for Standardization has initiated a revision of the OHSAS 18001 standard, setting itself the task of developing a new standard concerning the requirements for health and safety in the working process management systems. As a result, ISO 45001 is presented with a working title: Occupational health and safety management systems - Requirements with guidance for use. It is believed that through applying it, the harmonization of existing health and safety management systems will be achieved, as well as sharing good practice in the field. It is believed that ISO 45001 will be able to integrate with other management systems, taking into account the dynamic environment in which organizations operate today and the need to improve organizations' capabilities to overcome the risks to staff safety. As specified in ISO / DIS 45001.2, ISO 45001 Understanding the new international standard for occupational health \& safety (2017) will be the first worldwide standard for healthy and safe working conditions that will guarantee that organizations can create favourable conditions for work in order to prevent accidents at work and incidents. The implementation of this standard should lead to the improvement in the sustainability of the organization as it will be able to predict, prepare and adapt to upcoming amendments to provide further development by improving occupational health and safety. It is considered that using ISO 45001 will create opportunities for more effective risk management, as organizations improve their ability to determine and manage them thus, to be more sustainable. The integrated approach set out in the standard should help maintain consistency and alignment of various standards for management systems in accordance achieving a high level of commitment from senior management in a such way.

In accordance with the amendments adopted by the International Organization for Standardization, the new standards are being developed with the help of a new high-level structure (High Level Structure) called Annex SL. It determines the framework for the management system, which requires the adoption of three basic concepts, namely: the context of the organization, leadership and documentation of the information. On this basis, as stated by C. Caldwell (2016), the ISO 9001: 2015, ISO 14001: 2015, ISO 27001: 2013 standards have been developed. ISO 45001 is also based on it, as a result of which there are the following components: (1) scope, (2) legal references, (3) conditions and definitions, (4) context of the organization, (5) leadership, (6) planning, (7) support, (8) operation, (9) performance evaluation, (10) improvement. Their features are presented in Table 1.

ISO 45001, unlike OHSAS 18001, draws attention to the risk that is typical of the latest revision made in 2015 for the remaining standards.

As the main advantage of a standardized health and safety management system, it can be indicated that it would lead to the reduction and prevention of accidents, incidents, diseases at the workplace, and, respectively, to the reduction of the risk of causing harm to staff. The entire value chain is considered 
in order to determine the benefits to organizations in financial aspect. As a rule, ISO 45001 should be considered as a voluntary management tool, applying which organizations can minimize the risk of endangering human health or even eliminate it. The work on ISO 45001 is expected to be finalized and to be published in March 2018.

\begin{tabular}{|c|c|}
\hline Clause & Peculiar properties \\
\hline (1) Scope & $\begin{array}{l}\text { Specifies the requirements for the health and safety management } \\
\text { system and guidelines for their application. }\end{array}$ \\
\hline (2) Legal references & There is no change. \\
\hline (3) Conditions and definitions & $\begin{array}{l}\text { The used terms are shown. The changes to the definitions are } \\
\text { highlighted, among which are: } \\
\checkmark \text { "hazard identification" is replaced by "risk identification" and } \\
\text { "risk control" in order to be applicable in all areas of human } \\
\text { activity, while "hazard" is primarily linked to production; } \\
\checkmark \text { risk has a broader scope, including tasks that are given to } \\
\text { external contractors; } \\
\checkmark \text { the scope of the terms "worker / employee" and "workplace"; } \\
\checkmark \text { "compliance obligations" is changed to "legal and other } \\
\text { requirements"; } \\
\checkmark \text { "preventive actions" have been dropped as ISO } 45001 \text { aims to } \\
\text { prevent the occurrence of accidents and incidents; } \\
\checkmark \text { "documented information" replaces "documents and records". }\end{array}$ \\
\hline (4) Context of the organization & $\begin{array}{l}\text { Identification of internal and external factors and concerned parties } \\
\text { that affect the intended result. }\end{array}$ \\
\hline (5) Leadership & $\begin{array}{l}\text { Top management should define the policy, goals and establish } \\
\text { appropriate conditions for communication with the staff at all } \\
\text { levels of the organization to develop and promote a culture that } \\
\text { supports the Health and Safety Management System, full legal } \\
\text { compliance and continuous improvement. }\end{array}$ \\
\hline (6) Planning & $\begin{array}{l}\text { It is an ongoing process that predicts the changing circumstances. } \\
\text { It covers the identification of risks and opportunities and how they } \\
\text { can be proactively managed. }\end{array}$ \\
\hline (7) Support & $\begin{array}{l}\text { Identification of the resources needed to establish, implement and } \\
\text { maintain the management system, including suitably qualified } \\
\text { personnel, material and financial resources, infrastructure. }\end{array}$ \\
\hline (8) Operation & $\begin{array}{l}\text { Implementation of the developed plans and the assigned processes. } \\
\text { Development of controls to reduce risks to acceptable low levels. }\end{array}$ \\
\hline (9) Performance evaluation & $\begin{array}{l}\text { Identification of the necessary information and the observations } \\
\text { that should be made in order to assess the level of effectiveness of } \\
\text { the health and safety conditions in the organization. }\end{array}$ \\
\hline (10) Improvement & $\begin{array}{l}\text { Similar requirements for corrective action in relation to incidents } \\
\text { and nonconformities are put in place. The focus is on the } \\
\text { organization that should increase the value of interventions in the } \\
\text { field of health and safety at work. }\end{array}$ \\
\hline
\end{tabular}

Table 2 Number of valid certificates by the type of standards

\begin{tabular}{|l|r|}
\hline \multicolumn{1}{|c|}{ Type of Standart } & \multicolumn{1}{|c|}{ Number of Cerificates } \\
\hline ISO 9001 & 1943 \\
\hline ISO 14001 & 590 \\
\hline ISO 27001 & 118 \\
\hline ISO 22000 & 79 \\
\hline OHSAS 18001 & 476 \\
\hline HACCP & 38 \\
\hline
\end{tabular}

Source: Association "Club 9000" 


\section{Dissemination of OHSAS 18001: 2007 in Bulgaria}

In Bulgaria, by the end of October 2017, the number of certified organizations is distributed as follows (see Table 2):

As can be seen from the table, the greatest interest is shown in the basic quality management standard ISO 9001, followed by the ISO 14001 environmental management system standard. OHSAS 18001 is ranked third in the country in the number of valid certificates. Overall, the data shows that there is a certain decrease in the total number of registered certificates compared to the first half of 2017, which is slightly less than $4 \%$. The reason for this is the limited period of validity of certificates ( 3 years), after which not all organizations renew their certificates. The analysis of statistical data shows that in a summarized version, valid certification data is maintained in two groups - distributed by sectors and regions, as there is a high degree of unevenness in each of the two groups.

Data analysis also shows that most OHSAS 18001 certificates have been registered by organizations operating in the construction sector - 36\% of all certificates. Followed by organizations with the scope of activity Engineering Services - almost 13\% and Wholesale and Retail; Repair of Motor Vehicles, Motorcycles and Personal and Household Equipment - almost 12\%. A relatively small share of all (1\%) possess Processing and Non-metallic Mineral Products. At the same time, there are several sectors of the economy in which there is only one OHSAS 18001 certified organization, namely: Public Administration, Education, Health and Social Activities, Medicines, Agriculture and Fisheries (see Figure 1).

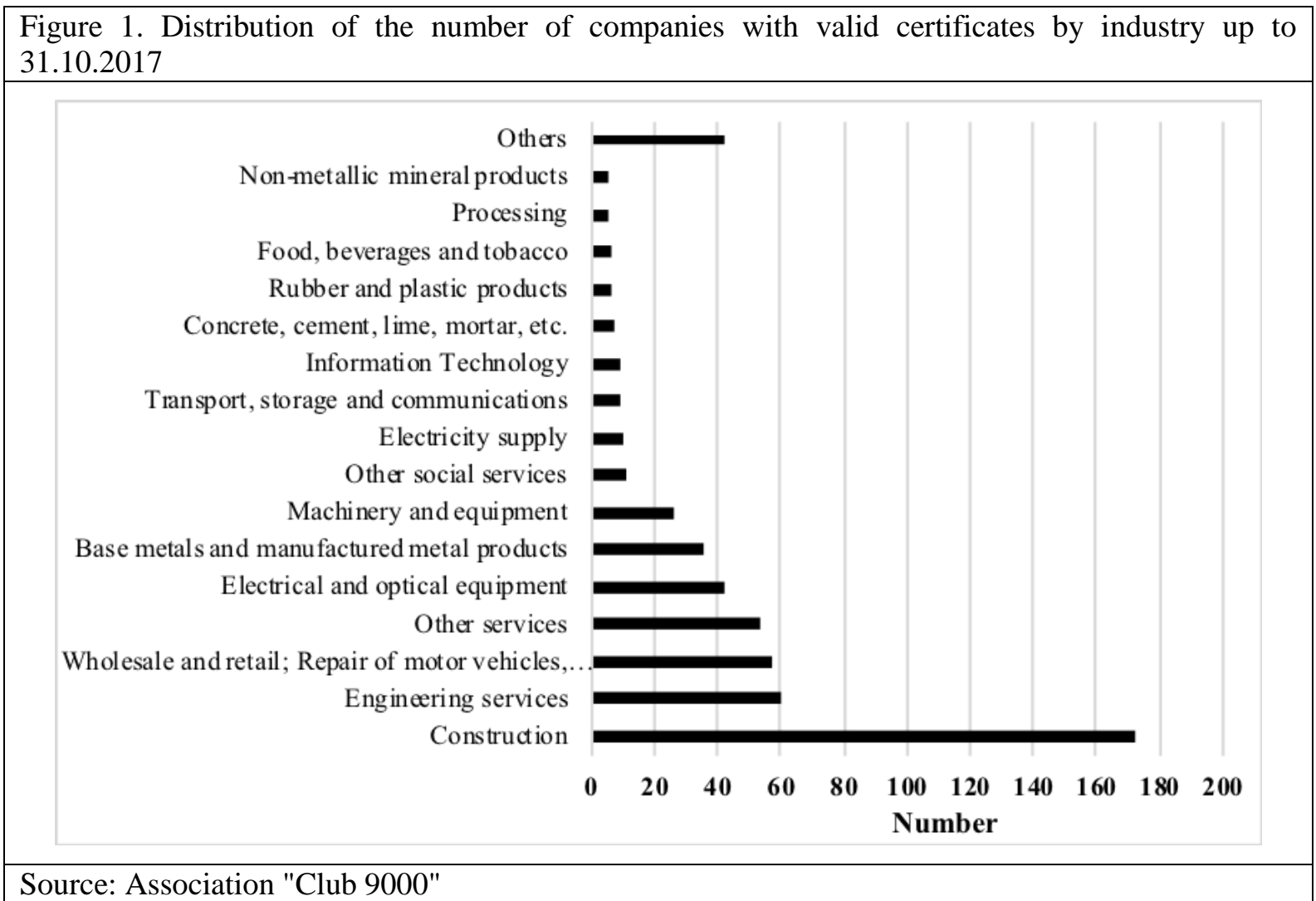

Regarding the region, priority is shown by organizations operating in the capital of the country, with almost 35\% of OHSAS 18001 certified companies in Bulgaria are concentrated in Sofia, following this is the city of Varna at $11 \%$ of the certified companies, followed by Plovdiv (6.9\%) and Burgas (6.7\%). In Veliko Tarnovo, Dobrich, Sliven, Targovishte, Shumen and Yambol, 1,3\% of OHSAS 18001 certificates are registered (see Figure 2). At the same time, the towns of Vidin and Silistra show only one certificate. The reason for this can be found in the significantly weaker economic development of these towns and villages, as a result of which the provision of sufficient funds for investment in certification of the organizations is an impassive task in financial terms for most of them. 


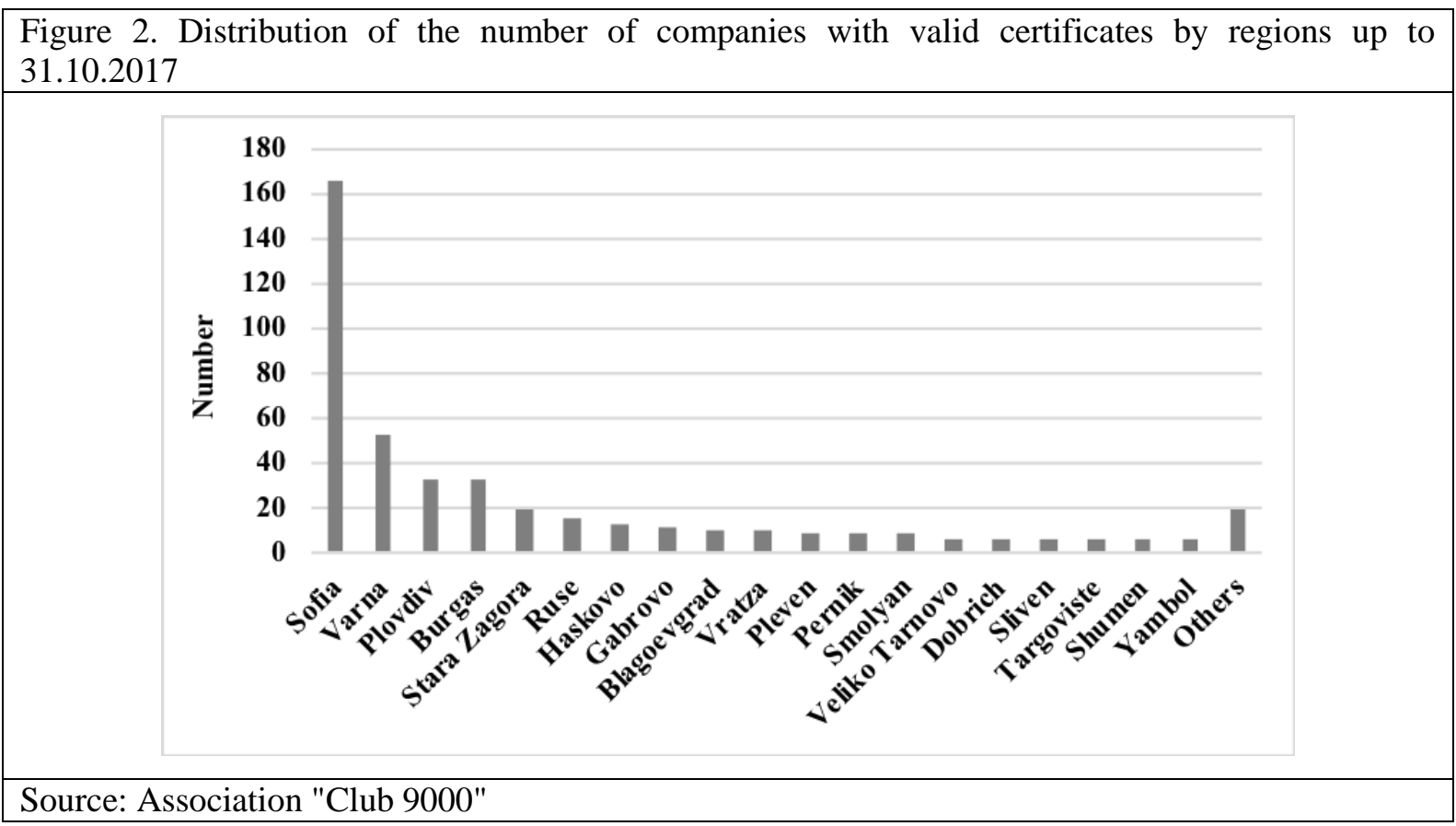

Action should be aimed to support organizations in adopting the OHSAS 18001: 2007 requirements by providing additional support, including financial, to bring the system into compliance with them. At the same time, certification should be seen as a means of enhancing the organization's competitiveness, improving its image among the employees and potential human resources that can be attracted at a subsequent stage, and overall improvement in working conditions for the staff. Special attention should be paid to those regions that are in the worst economic situation in order to give the opportunity for business development there. In this case, these are rather small towns and villages in Bulgaria.

\section{Conclusion}

The development of ISO 45001 in accordance with Annex SL is a prerequisite for the easier integration of this standard with others and the establishment of an effective quality management system in organizations. The development of an integrated management system is a prerequisite for achieving higher efficiency and effectiveness of the resources used. In this context, the implementation of ISO 45001 in more organizations in Bulgaria should be encouraged, as well as recertification after the expiration of the validity period of the certificate. This would ensure greater security for employees in every single organization and especially in those sectors where the risk to human health and safety is high. Initially, following the official publication of the new standards, all companies that currently have OHSAS 18001: 2007 certification should be encouraged to receive ISO 45001 certification.

\section{References}

Association "Club 9000" // www.club9000.org

Caldwell, C. ISO 45001:2016. The New International Standard for Occupational Health and Safety Management Systems: A short and simple guide. [Web blog post]. Retrieved from www.newground.co.uk

ISO/DIS 45001.2 Understanding the new international standard for occupational health \& safety (2017). [Web blog post].

Retrieved from bsigroup.com

Ling, T., Hashim, F., Liang, C. (2015). Occupational Health and Safety Advisory Services (OHSAS) 18001 Management System Adoption: Assessing the Determinants. Jurnal Pengurusan 43(2015) pp. $61-72$

New International Occupational Health \& Safety Management System. Executive Briefing (2016) [Web blog post]. http://bsigroup.com/ohsas-18001-occupational-health-and-safety/ISO-45001

NQA. // https://www.nqa.com/bg-bg/certification/iso-updates/iso-45001.

OHSAS 18001 TO ISO 45001 GAP GUIDE (2016) [Web blog post]. NQA/GA/45001/25Feb16. www.nqa.com/ISO45001 